OPEN ACCESS

Edited by:

Carlos Roncero,

University of Salamanca Health

Care Complex, Spain

Reviewed by:

Harry Lai,

University of Sydney, Australia

Felix Henrique Paim Kessler,

Federal University of Rio

Grande do Sul, Brazil

${ }^{*}$ Correspondence: Andreas Schindler,

a.schindler@uke.de

Specialty section: This article was submitted to

Addictive Disorders,

a section of the journal

Frontiers in Psychiatry

Received: 30 April 2019 Accepted: 10 September 2019

Published: 15 October 2019

Citation:

Schindler A (2019) Attachment and Substance Use Disorders - Theoretical Models, Empirical Evidence, and Implications for Treatment.

Front. Psychiatry 10:727. doi: 10.3389/fpsyt.2019.00727

\title{
Attachment and Substance Use Disorders - Theoretical Models, Empirical Evidence, and Implications for Treatment
}

\section{Andreas Schindler*}

Department for Personality and Stress Disorders, Center for Psychosocial Medicine, University Medical Center HamburgEppendorf, Hamburg, Germany

Introduction: The article reviews attachment-oriented research in individuals with substance use disorders (SUDs). Based on attachment theory, substance abuse can be understood as "self-medication," as an attempt to compensate for lacking attachment strategies. Attachment theory suggests a developmental pathway from insecure attachment to SUD and, on the other hand, a negative impact of substance abuse on attachment security. Earlier reviews have indicated a general link but have been inconclusive with regard to other aspects. In the light of a growing body of research, this review is looking for evidence for the general link, for its direction, for differences due to different patterns of attachment, different substances and severities, comorbid psychiatric disorders, and age groups.

Methods: Using medical and psychological databases, 34 cross-sectional studies, three longitudinal studies, and a systematic meta-analysis were identified. Methodological problems such as poor assessment of SUD and the use of different measures of attachment limit comparability.

Results: All cross-sectional studies in the review confirm a link between insecure attachment and SUD. Results of longitudinal studies show insecure attachment to be a risk factor for SUD, while continued substance abuse impairs the ability to form close relationships. With regard to specific patterns of attachment, results mainly point toward very insecure patterns. They indicate different patterns of attachment in different groups of substance abusers, suggesting different developmental pathways. Fearful-avoidant attachment was frequent in heroin addicts, while alcohol abusers displayed more heterogeneous patterns. Comorbid mental disorders and severity of SUD seem to be important factors, but data are still inconclusive. The link between insecure attachment and SUD seems to be stronger in adolescence compared to adulthood.

Discussion: The last decades have seen a substantial growth in studies on attachment and SUDs. Despite methodological problems, the general link between insecure attachment and SUD today is well established. Attachment theory might contribute to 
the understanding and treatment of SUDs in a significant way. But to do so, a lot of open questions have to be answered. We will need more carefully designed longitudinal studies, more studies connecting psychological data with brain processes, and more clinical trials.

Keywords: Attachment, attachment theory, patterns of attachment, substance use disorders, substance abuse, addiction

\section{INTRODUCTION}

Over the last decades, attachment theory (see BOX 1 for a brief description of attachment theory) has been applied to a lot of developmental and clinical fields, including substance use disorders (SUDs). A growing number of attachment-based studies have tried to contribute to the understanding of SUDs. In 2005, a first review tried to structure the field (1). It contained two main questions:

1. Is there a link between attachment and SUD?

2. Is there a link between one or several specific attachment patterns and SUD?

Additionally, it asked for the direction of these possible links, that is, for developmental pathways between attachment and SUD. It looked for differences between different age groups, between users of different substances, due to different levels of severity of SUD (use, abuse, addiction) and due to different comorbid psychiatric disorders. This first review identified 12 studies published between 1990 and 2005. Results indicated a link between insecure attachment and SUD, but they were inconclusive with regard to any other question. In the light of a growing body of research, this article is going to readdress the questions of the 2005 review. It tries to give a concise overview over what we know today about individual patterns of attachment among consumers of psychotropic substances. This might help to prepare the ground for a possible later integration of attachment in a multifactorial model of SUDs [see West and Brown (2), for an overview over addiction theories] and in the treatment of SUDs. Note that this review will not cover the topic of addictive behaviors such as gambling disorder or internet gaming disorder. And it will not cover the vast body of research on attachment in children of substance-abusing parents. This article will first give a theoretical introduction and sum up what we know from earlier reviews. It will then move on to methodological issues and to a review of the evidence represented in empirical studies today.

\section{Insecure Attachment and Substance Use Disorders}

Human beings who do not experience a sufficiently secure base develop insecure patterns of attachment, including negative IWMs of themselves and others, and negative expectations with regard to relationships (this includes therapeutic relationships, making it more difficult to establish a treatment alliance). Although insecure attachment is not a pathological condition in itself, it is related to mental disorders. Its ratio in clinical samples is $86 \%$, in contrast to $42 \%$ in the general population (9). It is seen as an important risk
BOX 1 | What is attachment?

"Attachment is a motivational, behavioral, and interactional system that provides security for immature offspring in a variety of species. The attachment system regulates distance and closeness of parents (or 'attachment figures') and children. The child will seek closeness to his/her parents whenever he/she feels in danger. Ideally, parents will then comfort the child, calm him/her down, and give him/her a rewarding feeling of security. This feeling of security or 'secure base' created in early attachment experiences helps the child to regulate his/her emotions and is an important step on the way to acquiring own coping strategies when facing fear or distress. Against the backdrop of a 'secure base', the child can explore his/ her environment (3-5). At the same time, secure attachment is the base for an exploration of his/her own inner world and that of others, that is, for the ability to 'mentalize' and to gain a coherent picture of mental processes (6). Over time, experiences with attachment figures are internalized. The child develops cognitive representations ['inner working models' ('IWMs')] of himself/herself and of his/her attachment figures. If positive IWMs are developed, other persons than the original attachment figures can also become a secure base. Additionally, positive IWMs make it possible to regulate affective states autonomously without depending on another person. In this sense, 'secure attachment liberates' (7)." (8, p. 305).

factor not only for SUD, but also for mental disorders in general (10). With increasing insecurity, individuals will face more difficulties in regulating emotions and stress. This regulation will not function either with the help of attachment figures or with the use of IWMs. At the same time, insecure individuals will face difficulties in forming and maintaining relationships with others. Psychotropic substances then might become attractive as one way to "self-medicate" attachment needs, to regulate emotions, to cope with stress, and to replace relationships $(8,11,12)$. Earlier reviews have shown cross-sectional evidence for a link between insecure attachment and SUDs $(1,8,10,13,14)$. Additionally, they have reported preliminary longitudinal evidence for insecure attachment being a risk factor for later substance abuse. This review will look for a replication of the general link and for more longitudinal data.

Although most theoretical and empirical work has focused on insecure attachment as a risk factor for the development of SUDs, it is likely that substance abuse has an effect on attachment, too. The consequences of substance abuse are a host of well-known developmental risks and neurological impairments (15). From an attachment perspective, four mental processes might be directly affected by substance abuse. First, exploration of the environment is reduced or distorted, or risks are taken that would never have been taken in a state of sobriety (16). Second, mentalization, the exploration of the inner, mental world of oneself and others is reduced (17). This might even be a possible motivation for substance abuse: nonmentalization and 
nonperception of distress and painful memories. Third, ageappropriate experiences in relationships often are inhibited or even prevented (18). Fourth, affect regulation and reward might be replaced by substance abuse (19). Further indirect evidence comes from the host of studies in samples of substance-abusing parents. These parents are hardly able to establish secure attachment relationships with their offspring (20). In sum, substance abuse might well have a negative impact on the ability to attach and form close relationships. Earlier reviews failed to provide empirical evidence regarding this point. This review will look for longitudinal evidence for an impact of substance abuse on attachment.

\section{Individual Patterns of Attachment and SUDs}

Attachment theory describes different patterns, which are based on the specific experiences in attachment relationships. They involve different levels of security, different strategies of coping with negative experiences in close relationships, and different means of regulating negative affect and expressing attachment needs. Individuals with preoccupied (sometimes called ambivalent/enmeshed/anxious) patterns use affectively hyperactivating strategies and are seeking closeness to important others. They are preoccupied with their own distress and the availability of attachment figures. Individuals with dismissing-avoidant strategies, on the other hand, tend to use distancing, affectively deactivating strategies. They defensively turn their attention away from their emotional distress and their attachment figures. A third group of patterns is characterized by a lack of functioning coping strategies and the highest risk for the development of severe psychopathology: disorganized patterns of attachment. These are associated with parental psychopathology (SUDs among others), with traumatic experiences (sexual abuse and maltreatment) as well as loss and neglect (21). While attachment originally described these patterns as categories, a dimensional approach seems to represent the existing data more precisely (22). Figure 1 presents a two-dimensional model of attachment patterns, trying to integrate the different constructs. Note that this model is only meant to give a rough orientation. The dimension secure-insecure is well established. Especially the definition of secure attachment is common ground. However, there are very different concepts describing the insecure end of this dimension (disorganized, unresolved, fearful-avoidant, hostile-helpless). Although these concepts are different, they share the lack of adaptive coping strategies and a high risk for developing mental disorders. The second dimension is generally labeled "coping style" with preoccupied patterns on the lefthand side and dismissing-avoidant patterns on the right-hand side. Two-dimensional models of attachment patterns often use the dimensions of anxiety and avoidance (23). This is a factor solution that is rotated by $45^{\circ}$ to the one described here (Figure 1). For more detailed discussions of these concepts, see Ravitz et al. (24) and Shaver and Mikulincer (22).



FIGURE 1 | Two-dimensional model of attachment. 
Evidence presented in earlier reviews was inconclusive with regard to specific patterns of attachment. While some studies pointed to more avoidant patterns in substance abusers ( 1 ), others indicated links with different patterns $(8,10,14)$. There had not been any longitudinal data on possible developmental pathways from specific patterns toward SUD. The relation between specific patterns and SUD is still an open question to be addressed in this review.

\section{The Use of Different Substances}

According to the "self-medication hypothesis" (12), the abuse of specific substances might be an attempt to cope with specific forms of emotional distress. For example, the abuse of stimulants might be linked to more hyperactivating, closeness-seeking attachment strategies, while the use of sedatives might be linked to deactivating, distancing strategies. Following the opioid deficit hypothesis (25; see Box 2), abuse of heroin and other opioids might be linked to extremely insecure attachment.

Despite some data from studies in alcohol and heroin using samples, earlier reviews have been inconclusive. The question of attachment-related differences between users of different substances will have to be addressed in this article.

\section{Severity of Substance Use}

In theory, more insecure individuals face a higher risk for developing SUDs. This does not necessarily imply that they develop more severe forms of SUDs. But if substance abuse impaired the attachment system, severity of abuse might be linked to severity of impairment. The review by Iglesias et al. (14) reported some evidence for a difference between experimental substance use and substance abuse in adolescent samples. The evidence in earlier reviews is limited, so it is still an open

BOX 2 | Neurobiological research and the reward-deficiency hypothesis.

Neurobiological research has focused on motivational processes of both attachment and substance abuse (26-29). Both are transmitted by the same mesolimbic and mesocortical circuits, and for both, dopamine, endorphins, oxytocin, and vasopressin play important roles. This line of research mainly relies on the reward-deficiency hypothesis of addiction $(30,31)$, assuming that psychotropic substances can substitute other "deficient" sources of reward. Attachment theory posits that insecure individuals have not sufficiently experienced the reward of a secure base. Their reward system tends to be insufficiently conditioned to satisfaction by social contact (29). Based on a host of animal studies on endorphins and opioids, Trigo et al. (25) have operationalized reward-deficiency as an opioid deficit. They assume that insecure attachment and insufficient conditioning to reward by social contact lead to a lack of endorphins in the VTA. As a consequence, dopaminergic reward processing in the limbic system cannot be released. This leads to a reward deficiency and increases the risk for addictive behaviors. Especially opioids might be a potent substitute for lacking attachment strategies. Recently, Alvarez-Monjaras et al. (19) have presented a multifactorial developmental model of attachment and addiction. The model basically assumes a functional interchangeability of attachment processes and substance use. According to this model, positive attachment experiences and secure patterns strengthen reward from social contact and decrease the risk for addictive behaviors. Negative attachment experiences and insecurity, on the other hand, lead to insufficient reward from social contact and to a heightened risk to replace it with addictive behavior (19). question: Does severity of substances use (use, abuse, addiction) make a difference with regard to attachment?

\section{Comorbid Psychiatric Disorders}

Comorbid psychiatric disorders are common in samples of substance abusers. Insecure attachment is not exclusively related to SUDs but to psychiatric disorders in general (10). Comorbidity might well be an important mediator of findings in this area. At the same time, it makes research very complex, because individuals with different comorbid disorders might use different substances for different reasons.

Schindler et al. (1) presented some limited evidence for different patterns of attachment in substance-abusing adolescents with different comorbid disorders. However, the question of the role of comorbid disorders in the relation between attachment and SUDs has to be readdressed.

\section{Age: Substance Abuse in Adolescence Vs. Adulthood}

The use and abuse of psychotropic substances usually begin and peak in adolescence. It is a crucial phase for the development of SUDs (11). At the same time, adolescence is important in the development of attachment. It is a transitional period when autonomy from parents, from the "secure family base," is developed $(32,33)$. This might suggest a closer relation between attachment and SUD in adolescence than in adulthood. Two earlier reviews have discussed these complex topics in detail (8, 14) but have not presented any data comparing adolescent and adult samples. This review will look for age-related effects with regard to attachment and SUDs.

\section{METHODS}

Literature for this review was scanned in PubMed/MEDLINE, Web of Science, PsycARTICLES/PsycINFO, PSYNDEX, EMBASE, and CINAHL databases for "all years" with a final update on April 4, 2019, using the following keywords: "attachment," "attachment theory," "patterns of attachment," "substance use disorders," "substance abuse," and "addiction." Additionally, references in articles and presentations were tracked. Criteria for inclusion were original empirical studies; basic research standards are met (which was not the case in studies earlier than 1990); use of validated measures of attachment; study based on attachment theory; focus on attachment of substance using individuals (this excluded studies focusing on children of substance users); and assessment of substance use, abuse, or addiction. Five hundred forty-six publications were scanned. After removing duplicates and studies not meeting the criteria, we included 37 original studies on attachment and SUD and one quantitative meta-analysis. Three of the original studies were longitudinal. Two further studies had a longitudinal design, but reported only cross-sectional data for the question at hand. See Figure 2 for a flowchart of the selection process. 
Search of databases (PubMed/Medline, Web of Science, PsycArticles/ PsycInfo, Psyndex, Embase, Cinahl) and references

Period of time: "all years" (final update on April 4th, 2019)

Terms: "Attachment", "attachment theory", "patterns of attachment", "substance use disorders", "substance abuse", "addiction"

$(\mathrm{n}=546)$

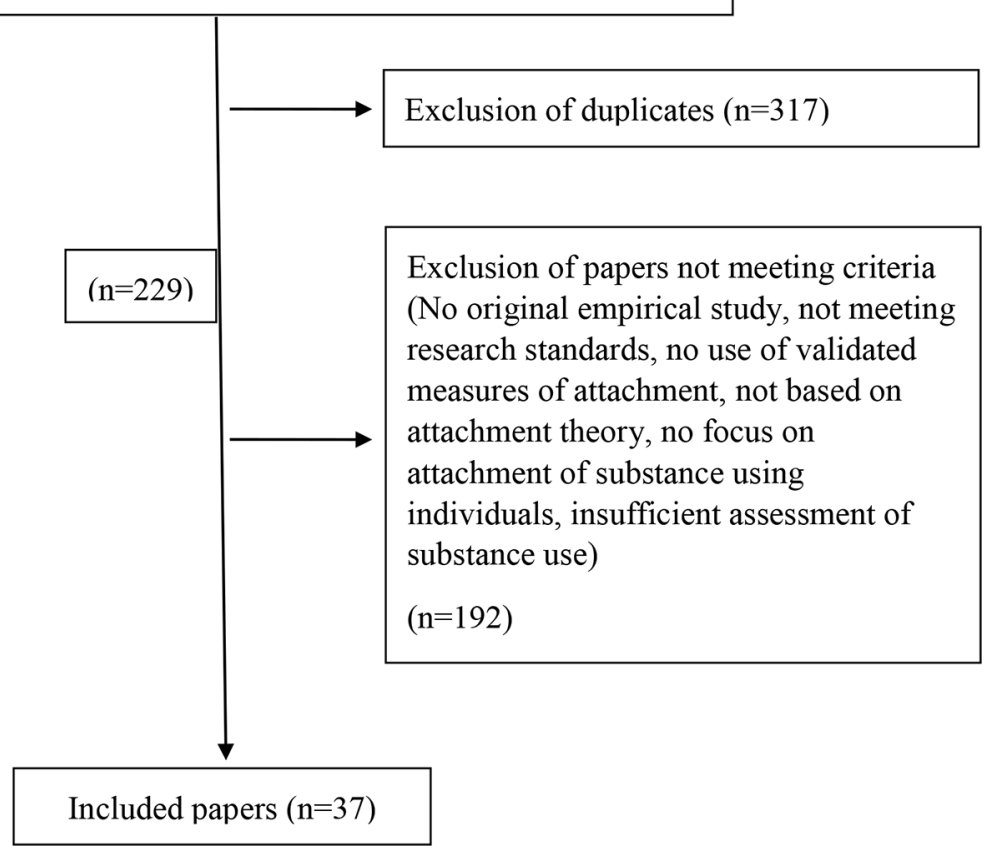

FIGURE 2 | Flowchart study selection.

Although we only included studies grounded in attachment theory, the use of different attachment measures makes results difficult to compare results. Additional methodological problems arise from flaws in the assessment of substance abuse and in sample selection. Samples were very heterogeneous, including different substances and different stages of severity. Most studies relied on self-report measures of substance use, with urinalyses or similar physical measures being rare.

\section{Measures of Attachment Patterns}

Attachment research has developed different measures. These share the basic distinction between secure and insecure attachment, but differ in the definition and labeling of specific patterns. While attachment interviews assess attachment representations, defined as the state of mind with regard to early attachment experiences, self-report questionnaires assess attachment styles, defined as experiences and behavior in close relationships (including romantic relationships). Although attachment theory assumes that these patterns develop in early childhood, both types of measures assess the current state of the attachment system. Attachment questionnaires and interviews show moderate correlations. The majority of studies use self-reports, which are seen as "surface indicators" of attachment representations $(22,24)$. The Adult Attachment Interview (AAI) (34) is a semistructured interview with four categories: secure-autonomous, preoccupied, dismissing, and unresolved. The category "hostile-helpless" was added later to describe special patterns mainly occurring in clinical samples (35). The Adult Attachment Projective (AAP) (36) is a projective test designed to produce narratives that can be categorized in the same way as the AAI. The Hazan and Shaver Self-report (HSSR) (37) is a simple measure consisting of brief descriptions of three attachment styles with respect to experiences in romantic relationships. Attachment styles are called secure, anxiousambivalent, and avoidant. Note that avoidance is rather defined as fearful-avoidance in the Bartholomew model (high insecurity, no coping) and not as dismissing avoidance in the AAI. The Adult Attachment Scales (AAS) (38) is a multi-item scale based on the HSSR. It assesses secure, anxious, and avoidant attachment styles. Note that anxious attachment here is defined as the high end of the anxiety scale. Bartholomew and Horowitz (23) developed a model of four attachment categories, based on positive and negative internal working models of the self and of others. Bartholomew differentiated between two avoidant categories: fearful-avoidant 
(according to the HSSR) and dismissing-avoidant (according to the AAI) (Figure 1). Based on this model, several self-report measures such as the Relationship Questionnaire, the Relationship Scale Questionnaire (39), the Experiences in Close Relationships (40), and an Attachment Interview have been developed (23).

\section{RESULTS}

\section{Insecure Attachment and SUDs}

All studies in this review report a link between insecure attachment and substance abuse or addiction (Table 1). Secure attachment was typically found in healthy controls in all studies including a control group. Cooper et al. (41) additionally showed a relation with experimental substance use in adolescence.

Three longitudinal studies indicate that attachment in an earlier age has an impact on later substance abuse. Branstetter et al. (44) demonstrated that securely attached adolescents at age 14 years consumed fewer substances at age 16 years. Danielsson et al. (77) showed that attachment security at age 13 years prevented heavy drinking episodes at age 15 years. In a study by Zhai et al. (76), insecure attachment at age 10 to 12 years led to dysregulation at age 16 years and substance abuse at age 22 years. In a meta-analytic calculation, Jordan and Sack (78) calculated that secure attachment decreases the risk for substance abuse by odds ratios ranging from 0.60 to 0.70 . Thus, the risk for substance abuse is about one-third lower for securely attached adolescents.

The impact of substance abuse on attachment security has been studied less frequently. Unterrainer et al. (57) found such an impact with a strong neurotoxic effect in a clinical study of long-term addicts. Nonclinical studies have been less conclusive (79). A recent quantitative meta-analysis of prospective longitudinal studies (80) analyzed 34 original studies with as many as 56,721 participants. Studies mainly investigated community or college samples with a mean age of 15 years (range, 7-30 years); they covered a mean period of time of 3.8 years, and they mainly used attachment self-reports. The analysis yielded significant prospective relations in both directions with a significantly stronger effect of insecure attachment on substance abuse than vice versa.

\section{Individual Patterns of Attachment: Styles and Representations}

Data from longitudinal studies do not provide any information about different developmental pathways of individuals with specific patterns of attachment. However, the last three decades have seen a substantial growth of cross-sectional studies. Eight studies were carried out with the AAI/AAP. Six used the HSSR, and another six the AAS. Fourteen studies used measures based on the Bartholomew model. Three studies used other measures Attachment and Clinical Issues Questionnaire, Youth Attachment to Parents Scale, Inventory of Parent and Peer Attachment (ACIQ, YAPS, IPPA). Before describing results in detail, here is a brief overview:

- AAI/AAP studies mainly show dismissing and unresolved representations.

- In HSSR studies, fearful attachment was the most frequent style.

- AAS studies mainly report anxious attachment styles.
The majority of studies used the Bartholomew model point toward fearful-avoidance, with some evidence for a link with the anxiety dimension.

\section{AAI/AAP Studies}

A small German study (43) found dismissing and unresolved representations in adolescent drug addicts using multiple substances. Two other studies examined samples of adolescents in psychiatric inpatient treatment with SUD and other psychiatric diagnoses. Rosenstein and Horowitz (50) found partly dismissing and partly preoccupied representations in substance abusers with different comorbid disorders. Allen et al. (51) report a relation between "hard drug use" and dismissing attachment. Although this study had a longitudinal design, results concerning attachment and SUD were cross-sectional. Studies in adult samples found hostile-helpless representations $(35,45)$ among African American mothers in methadone maintenance treatment, a general link to insecurity in a sample of adults who had been adopted in childhood $(46,47)$ and unresolved representations among expecting parents (48), among substance-abusing psychiatric inpatients (49), and among adult drug addicts (using the AAP; 42).

\section{HSSR Studies}

HSSR studies mainly examined nonclinical samples. While a high-school study reported a link between anxious attachment and "problematic" substance abuse (41), the majority of substance abusers in a large representative US-wide sample described themselves as avoidant (53). So did the majority of "heavy drinkers" in college (54) and young adult samples (55), as well as adult longterm heroin addicts in Israel (52).

\section{AAS Studies}

Most AAS studies report anxious attachment in substanceabusing college students (60), in alcohol abusers in Korea (59), in alcohol addicts (61), and heroin addicts (57). An exception is the study by Durjava (56), which reports heightened scores on all insecure scales in heroin addicts.

\section{Studies Using Measures Based on the Bartholomew Model}

Studies in college samples mainly found links between alcohol abuse and fearful-avoidant patterns, while preoccupied and dismissing patterns occurred less frequently $(68,73,74)$. The same constellation of patterns were found in clinical samples of substance-dependent individuals $(18,62,64,72)$. In samples of heroin addicts, fearful-avoidant attachment was the main pattern $(1,52,71)$, while alcohol addicts showed either preoccupied (67) or generally insecure attachment $(65,69,70)$. A study in adults in primary care found hazardous drinking to be linked to the anxiety dimension (63). Jenkins and Tonigan (66) found elevated attachment anxiety in an Alcoholics Anonymous (AA) sample. Although this study had a longitudinal design, results concerning attachment, and SUD were cross-sectional.

\section{Different Substances}

Only two studies compare users of different substances systematically. Zeid et al. (75) did not find any differences 
TABLE 1 | Studies on attachment and substance use disorders

\begin{tabular}{|c|c|c|c|c|c|c|c|c|}
\hline Authors, Year & Age group & Sample & N/controls & Substances & Severity & Method & $\begin{array}{l}\text { Measure of } \\
\text { attachment }\end{array}$ & $\begin{array}{l}\text { Main attachment } \\
\text { pattern }\end{array}$ \\
\hline Delvecchio et al. (42) & Adult & Clinical, TSUD & $40 /-$ & Illicit drugs & Addiction & CS & AAP & Unresolved \\
\hline Amman (43) & Adolescent & Clinical, TSUD & $15 / 15$ & Unspec. & Addiction & CS & AAl & $\begin{array}{l}\text { Dismissing, cannot } \\
\text { classify, unresolved }\end{array}$ \\
\hline Branstetter et al. (44) & Adolescent & Nonclinical & $200 /-$ & Unspec. & Abuse & Long. & AAI, HSSR & $\begin{array}{l}\text { Insecure (mediated by } \\
\text { maternal monitoring) }\end{array}$ \\
\hline $\begin{array}{l}\text { Melnick et al. (35), } \\
\text { Finger (45) }\end{array}$ & Adult & Clinical, TSUD & $62 / 87$ & Heroin & Addiction & CS & AAl & Hostile-helpless \\
\hline $\begin{array}{l}\text { Caspers et al. (46), } \\
\text { Caspers et al. (47) }\end{array}$ & Adult & Nonclinical, adoptees & $208 /-$ & Unspec. & Use/abuse & CS & AAl & Insecure \\
\hline $\begin{array}{l}\text { Riggs and Jacobvitz } \\
\text { (48) }\end{array}$ & Adult & $\begin{array}{l}\text { Nonclinical, expect. } \\
\text { parents }\end{array}$ & $233 / 26$ & Unspec. & Abuse & CS & AAl & Unresolved \\
\hline Fonaghy et al. (49) & Adult & Clinical, psychiatric & $82 / 37$ & Unspec. & Abuse & CS & AAl & Unresolved, preoccupied \\
\hline $\begin{array}{l}\text { Rosenstein and } \\
\text { Horowitz (50) }\end{array}$ & Adolescent & Clinical, psychiatric & $60 / 29$ & Unspec. & Abuse & CS & AAl & Dismissing, preoccupied \\
\hline Allen et al. (51) & Adolescent & Clinical, psychiatric & $66 / 76$ & Illicit dr. & Abuse & CS (Long.) & AAl & Dismissing \\
\hline Finzi-Dottan et al. (52) & Adult & Clinical, TSUD & $56 / 56$ & Heroin & Addiction & CS & HSSR & Avoidant \\
\hline Cooper et al. (41) & Adolescent & Nonclinical & 2011/1151 & Unspec. & Use/abuse & CS & HSSR & Secure vs. anxious \\
\hline Mickelson et al. (53) & $15-54$ y & $\begin{array}{l}\text { Nonclinical, } \\
\text { representative }\end{array}$ & $8089 / 2876$ & Unspec. & Abuse & CS & HSSR & Avoidant (anxious) \\
\hline $\begin{array}{l}\text { Brennan and Shaver } \\
\text { (54) }\end{array}$ & Young adult & Nonclinical, college & $242 / 178$ & Alcohol & Use & CS & HSSR & Avoidant \\
\hline $\begin{array}{l}\text { Senchak and Leonard } \\
\text { (55) }\end{array}$ & Young adult & Nonclinical & $644 /-$ & Alcohol & Use/abuse & CS & HSSR & $\begin{array}{l}\text { Men: avoidant, women: } \\
\text { unrelated }\end{array}$ \\
\hline Durjava (56) & Adult & Clinical, TSUD & $54 / 54$ & Heroin & Addiction & CS & AAS & Insecure \\
\hline Unterrainer et al. (57) & Adult & Clinical, TSUD & $19 / 40$ & Heroin & Addiction & CS & AAS & Anxious \\
\hline Mortazavi et al. (58) & Adult & Clinical, TSUD & $60 / 60$ & Opium & Addiction & CS & AAS & Insecure \\
\hline Shin et al. (59) & Adult & Nonclinical, male & $141 /-$ & Alcohol & Abuse & CS & AAS & Anxious \\
\hline Kassel et al. (60) & Young adult & Nonclinical, college & $212 /-$ & Unspec. & Abuse & CS & AAS & Anxious \\
\hline Vaz-Serra et al. (61) & Adult & Clinical, TSUD, male & $56 / 56$ & Alcohol & Addiction & CS & AAS & Anxious \\
\hline Gidhagen et al. (62) & Adult & Clinical, TSUD & $108 /-$ & Unspec. & Addiction & CS & BSR & $\begin{array}{l}\text { Fearful (preoccupied, } \\
\text { dismissing) }\end{array}$ \\
\hline Le et al. (63) & Adult & Primary care & $348 /-$ & Alcohol & Abuse & CS & BSR & Anxiety dimension \\
\hline Schindler and Sack (64) & Adult & Clinical, psychiatric & $36 / 21$ & Unspec. & Abuse/Addiction & CS & $\mathrm{BAl}$ & Fearful (dismissing) \\
\hline Wedekind et al. (65) & Adult & Clinical, TSUD & $59 /-$ & Alcohol & Addiction & CS & BSR & Insecure \\
\hline $\begin{array}{l}\text { Jenkins and Tonigan } \\
\text { (66) }\end{array}$ & Adult & Alcoholics Anonymous & $253 /-$ & Alcohol & Addiction & CS (Long.) & BSR & Anxiety dimension \\
\hline Harnic et al. (67) & Adult & Clinical, TSUD & $40 /-$ & Alcohol & Addiction & CS & BSR & Preoccupied \\
\hline Molnar et al. (68) & Young adult & Clinical, TSUD & 213/696 & Alcohol & Abuse & CS & BSR & $\begin{array}{l}\text { Fearful (preoccupied, } \\
\text { dismissing) }\end{array}$ \\
\hline $\begin{array}{l}\text { DeRick and Vanhuele } \\
\text { (69), DeRick et al. (70) }\end{array}$ & Adult & Clinical, TSUD & $101 /-$ & Alcohol & Addiction & CS & BSR & Insecure \\
\hline Schindler et al. (71) & $14-29 y$ & Clinical, TSUD & $94 / 72$ & Heroin/XTC/THC & Addiction/abuse & CS & $\mathrm{BAI}$ & $\begin{array}{l}\text { Fearful vs. insecure vs. } \\
\text { dismissing }\end{array}$ \\
\hline Doumas et al. (72) & Adult & Clinical, TSUD & $46 /-$ & Unspec. & Addiction & CS & BSR & $\begin{array}{l}\text { Fearful (preoccupied, } \\
\text { dismissing) }\end{array}$ \\
\hline $\begin{array}{l}\text { Thorberg and Livers } \\
\text { (18) }\end{array}$ & Adult & Clinical, TSUD & $99 / 58$ & Unspec. & Addiction & CS & BSR & $\begin{array}{l}\text { Fearful (preoccupied, } \\
\text { dismissing) }\end{array}$ \\
\hline Schindler et al. (1) & $14-25$ y & Clinical, TSUD & $71 / 71$ & Heroin & Addiction & CS & $\mathrm{BAl}$ & Fearful \\
\hline $\begin{array}{l}\text { Vungkhanching et al. } \\
\text { (73) }\end{array}$ & Young adult & Nonclinical, College & $369 /-$ & Alcohol & Abuse & CS & $\mathrm{BSR}$ & $\begin{array}{l}\text { Fearful (preoccupied, } \\
\text { dismissing) }\end{array}$ \\
\hline McNally et al. (74) & Young adult & Nonclinical, College & $366 / 366$ & Alcohol & Use & CS & $\mathrm{BSR}$ & Fearful (preoccupied) \\
\hline Zeid et al. (75) & Adult & Clinical, TSUD & $149 / 92$ & Alcohol/. opiates & Addiction & CS & $\mathrm{ACIQ}$ & $\begin{array}{l}\text { Insecure (no difference } \\
\text { between groups) }\end{array}$ \\
\hline Zhai et al. (76) & $10-22$ y & Nonclinical & $694 /-$ & Unspec. & Abuse & Long. & YAPS & Insecure \\
\hline Danielsson et al. (77) & Adolescent & Nonclinical, community & $1222 /-$ & Unspec. & Use/abuse & Long. & IPPA & Insecure \\
\hline
\end{tabular}

TSUD, treatment of SUD; Unspec., substances not specified; CS, cross-sectional; Long., longitudinal; XTC, ecstasy; THC, cannabis; AAl, Adult Attachment Interview; AAP, Adult Attachment Projective; AAS, Adult Attachment Scale; ACIQ, Attachment and Clinical Issues Questionnaire; BSR, Bartholomew Self-report (RQ, RSQ, ECR); BAl, Bartholomew Attachment Interview; HSSR, Hazan \& Shaver Self-report; IPPA, Inventory of Parent and Peer Attachment; YAPS, Youth Attachment to Parents Scale.

between alcohol and opiate addicts. In contrast to this study, Schindler et al. (71) did find significant differences between heroin, ecstasy, and cannabis users and nonclinical controls. While heroin addicts were mainly fearful-avoidant, controls were mainly secure, and cannabis abusers tended to be dismissing-avoidant. Ecstasy (MDMA) abuse was related 
to insecure attachment, but not to a specific attachment pattern.

Studies in specific groups provide some additional information about heroin, alcohol, and cigarette smoking. With regard to heroin addiction, they indicate fearful-avoidance $(1,52)$, as well as hostile-helpless representations in the AAI (45) and insecurity in general in the AAS (56). Studies in samples of alcohol users also showed avoidant and highly insecure patterns, but higher rates of preoccupied/ambivalent attachment (67) and a relation with the anxiety dimension, too $(59,61,63,66)$. The metaanalysis of Fairbairn et al. (80) shows a close relation between attachment-based emotion regulation and cigarette smoking.

\section{Severity of Substance Use}

A comparison of studies in clinical versus nonclinical samples does not show any systematic differences in attachment patterns. Especially alcohol use, abuse, and addiction have been studied repeatedly without finding different patterns of attachment. However, results show a correlation between severity of opioid addiction and attachment insecurity. Opiate addicts in Iran were more insecure than nonaddicted opiate users (58). Severity of heroin use correlated with fearful-avoidant attachment $(1,62)$.

\section{Comorbid Psychiatric Disorders}

Rosenstein and Horowitz (50) report mainly dismissing classifications in adolescent substance abusers with comorbid conduct disorders but partly dismissing and partly preoccupied classifications in those with affective disorders. In a study of Schindler and Sack (64), comorbid patients with SUD and borderline personality disorder (BPD) were similar to other BPD patients in several psychiatric measures, but closer to SUD patients with regard to attachment. They were more avoidant and less preoccupied than other BPD patients. With regard to PTBS, three studies found a link between SUDs and unresolved attachment $(43,48,49)$, while two other studies did not find this relation in adolescent samples $(50,51)$.

\section{Age: Adolescent vs. Adult Samples}

The meta-analysis by Fairbairn et al. (80) shows a closer relation between insecure attachment and substance abuse in adolescents than in adults. In AAI studies in adolescent samples, dismissing attachment seems to be the most frequent representation, while adult samples mainly showed unresolved and hostile-helpless representations. Other studies do not indicate any systematic differences between adolescent and adult samples.

\section{DISCUSSION: IMPLICATIONS FOR RESEARCH AND TREATMENT}

\section{Insecure Attachment and SUDs}

A host of cross-sectional studies consistently replicated the finding of a general link between insecure attachment and SUDs. Secure attachment is only occurring in experimental substance users and in healthy controls. Evidence from psychological studies is in tune with neurobiological findings. Longitudinal studies and meta-analyses indicate that secure attachment is a protective factor against substance abuse, and insecure attachment is a risk factor for substance abuse. Taken together, the general link between insecure attachment and SUDs today is well established, and there is moderate to strong evidence for the assumption of insecure attachment being a risk factor for SUD.

Additionally, there is moderate meta-analytic longitudinal evidence for a negative impact of substance abuse on attachment. This effect might be linked to the severity of substance abuse. The study by Unterrainer et al. (57) suggests that it might be, at least in part, an unspecific effect of neurotoxic impairments caused by substance abuse. The negative psychological effects described above might have an impact, too, but there is no direct evidence in the studies reviewed. Indirect evidence comes from parenting studies, showing that substance abusers have serious problems to provide secure attachment for their offspring (20). In the light of existing data, a vicious circle between insecure attachment and substance abuse seems likely. But we will need more longitudinal studies to gain a more detailed picture of this interaction. Studies will have to use psychological as well as neurobiological measures to control for possible confounds.

\section{Different Patterns of Attachment}

It is more difficult to summarize the results of the 37 studies analyzing attachment patterns.

Their results mainly point toward very insecure patterns (unresolved-disorganized and hostile-helpless in the AAI, fearful-avoidant in the Bartholomew model). This supports the hypothesis of substance abuse as a substitute for deficient attachment strategies. But there is some evidence for other patterns as well, with avoidant patterns occurring more frequently than preoccupied or anxious ones. We still lack longitudinal data on developmental pathways from specific patterns toward SUD. Additionally, the selection of very different samples and the use of different measures make it difficult to draw conclusions. Differences between studies using different measures suggest a methodological bias. We need studies comparing different measures in one sample to discern these effects. Nonetheless, a lot of studies report different patterns within one sample, assessed with one measure. This suggests that different patterns are linked to SUD. From an attachment theory point of view, it seems likely that individuals with different patterns of attachment use psychotropic substances for different reasons. Individuals with preoccupied attachment might use substances to minimize social fears and to make it easier to get in touch with others. Individuals with avoidant patterns might use substances to avoid feeling negative emotions, attachment needs, and loneliness. Individuals with disorganized patterns might use substances to cope with fear and posttraumatic symptoms. Future research will have to consider different and complex pathways in a longitudinal design.

\section{Different Substances}

Results from two systematic comparisons of users of different samples are inconclusive. There is some evidence for a link between heroin use and extremely insecure patterns. Although studies used different measures, all found these extremely insecure 
patterns, ranging on the level of disorganization (Figure 1). This is in tune with the endorphin-deficit hypothesis (25), assuming that opioids might be especially attractive for highly insecure individuals. Preliminary data on alcohol abuse point to different patterns. Studies found relations with avoidant and highly insecure as well as preoccupied/ambivalent patterns. It seems possible that alcohol abuse can have different functions. It might be used to reduce social fears and support closeness seeking in preoccupied individuals. Avoidant or fearful individuals, on the other hand, might use higher doses to avoid contact and deactivate emotions. The only study exploring ecstasy (MDMA) expected a relation with preoccupied attachment but found generally insecure patterns. The "entactogenous" effect of ecstasy does not seem to be related to closeness seeking in the sense of attachment. Meta-analytic data point toward a relation between nicotine and affect-regulation in adolescence. In mainly nonclinical samples, cigarettes might be the drug of choice for those with insecure attachment and problems to regulate emotions. Research on different substances is still fragmentary. Several important substances (e.g., cocaine, benzodiazepines, methamphetamines, etc.) have not even been studied. Systematic comparisons are rare. Although it is too early to report any definite relations, there does not seem to be a general link between substance abuse and a single specific pattern of attachment. This renders future research more complex, facing a variety of substances and patterns of consumption. We will need more systematic comparisons of different groups. Studies should include neurobiological data, considering different substancerelated effects.

\section{Severity of Substance Abuse}

Data on the severity of substance abuse are inconclusive, too. Whereas a comparison of samples of alcohol abusers versus addicts did not show any systematic differences, three studies report a correlation between severity of opioid addiction and attachment insecurity. This is in tune with theoretical models, and it might hint at the special role of opioids. However, we need more studies to draw conclusions.

\section{Comorbidity}

Studies have addressed depressive, anxiety, conduct, borderline, and posttraumatic disorders, but we still lack knowledge from other important fields such as psychotic or bipolar disorders. Some studies showed different attachment patterns in substance abusers with comorbid conduct versus affective disorders. Another study reported differences between borderline patients with or without SUD. Posttraumatic stress disorders are special because they are linked to the concept of unresolved attachment and because clinical SUD samples show high rates of traumatic experiences (81). However, existing data on unresolved attachment and SUD are inconclusive. We still lack systematic studies on the relations between SUD, trauma, and unresolved attachment. Results on comorbid disorders in general show their relevance and the complexity of possible interrelations between attachment, SUDs, and comorbid disorders. But it is too early to draw any specific conclusions. Future research in clinical samples will generally have to take comorbidity into account.

\section{Age}

Cross-sectional studies do not indicate any systematic differences in attachment patterns between adolescent and adult samples. The differences found in AAI studies are difficult to explain. However, meta-analytic findings of a closer relation between attachment and SUD in adolescence are more conclusive and more in tune with expectations. They underpin the importance of the developmental phase. Adolescence should be a focus of future research within a developmental framework. Because of the significance of the family background, this research will have to include a family systems perspective (Table 2 ).

\section{Implications for Treatment}

Based on the results of this review, some implications for the treatment and prevention of SUD will be discussed. We still are at an early stage, lacking an integration of attachment in a model of SUD, lacking treatment concepts, and clinical trials.

Results suggest that treatment approaches should consider insecure attachment in SUD patients. Since there seem to be different types of insecure attachment, these should be assessed and become part of individual treatment planning in the same way as information about consumed substances, level of severity, and comorbidities is used. Attachment theory stresses the therapeutic alliance as a means to develop more attachment security. However, establishing such a relationship with insecure substance abusers is difficult. It will often require specific engagement strategies, and it needs to be adapted to the individual pattern of attachment. Fowler et al. (82) found higher rates of treatment retention in addicts with preoccupied patterns. It seems to be more difficult to establish a therapeutic relationship with avoidant or unresolved individuals. Data show that substance-abusing patients with BPD are more avoidant and more difficult to reach for treatment (64).

Abstinence is a precondition for most treatments and for forming a therapeutic relationship. From an attachment point of view, abstinence means that substance abusers have to do without their usual coping strategy, leaving them without any functioning strategy. At the same time they are asked to open up to others, a subjectively dangerous step, considering negative relationship expectations. So therapists need to monitor their patients' limited ability to get and stay in touch. From this perspective, relapses and treatment dropouts can be seen as avoidance of relationships.

Attachment-based approaches of individual treatment could be adopted for the treatment of SUD. To date, the most promising approach is mentalization-based therapy (MBT) (6). MBT is fostering the ability to mentalize, that is, to explore inner states of oneself and others. Preconditions of this ability are abstinence and felt security. The problem is that substance abusers usually do not feel secure at all when they reach abstinence. MBT for SUDs then has to take careful small steps, fostering security, keeping abstinence, and slowly exploring feelings and inner worlds. An ongoing RCT is currently evaluating MBT in a sample of opioid dependent adults in Sweden (17). 


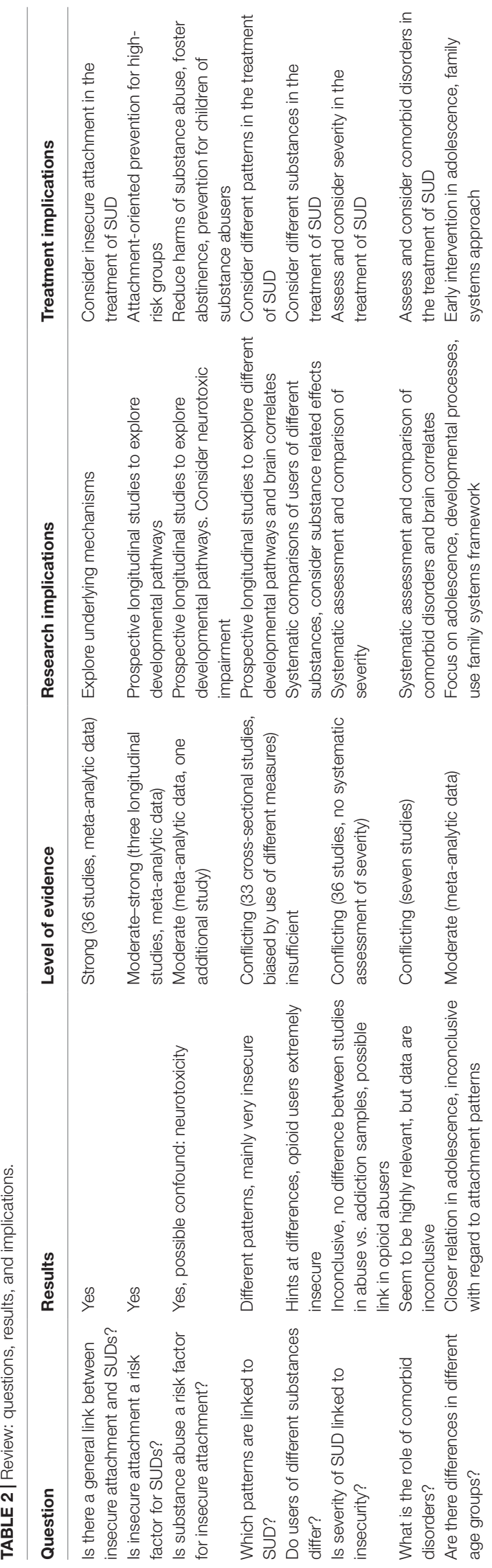

Longitudinal data show a bidirectional relation between insecure attachment and SUDs. This might have implications for treatment as well as prevention. It might become a vicious circle worsening both problems and a very challenging task to break this circle. Treatment has to focus on two goals that might reinforce each other in a negative or in a positive way. Quitting substance abuse will be easier when attachment security is fostered. The development of security, on the other hand, will benefit from abstinence. Gidhagen et al. (62) showed that it is possible to approach both goals successfully. They found an increase in attachment security in the course of addiction treatment.

The treatment of SUDs might help to prevent the development of even more insecure attachment. This should have a positive effect on relationships of substance abusers, including caregiving relationships with their children. Attachment-based prevention programs for children of substance-abusing parents are among the most elaborated and best evaluated approaches in the field (20). With regard to the prevention of SUDs, results suggest that fostering attachment security in childhood and adolescence might be effective. The importance of adolescence in the development of both attachment and SUD calls for early interventions designed for this age group. Among other things, this will need a family systems framework [Lewis (in this Frontiers Research Topic)]. Family treatments give a chance to treat attachment-related disorders in the context in which they have developed. Family therapy approaches for adolescent substance abusers are among the best evaluated treatments $(83,84)$. To date, there are two explicitly attachment-based approaches, attachmentbased family therapy (85) and mentalization-based family therapy (MBFT) (86). Although neither of these focuses on SUDs, it seems possible to integrate attachment-focused work into family therapy approaches for SUDs (87).

Finally, attachment research has stimulated the search for new medications, pointing toward the importance of oxytocin. This substance is now considered a promising therapeutic agent for alcohol use disorders (88).

\section{Strengths and Limitations}

This review has tried to give a concise overview over 30 years of research in the field. Since 2005, the number of studies has tripled, providing strong evidence for the general link between attachment and SUD. Meta-analytic and longitudinal evidence shows the interaction between attachment and SUD. Although results are still inconclusive in many regards, they indicate the need to differentiate between different patterns of attachment, different substances, comorbidities, and age groups. Results show the potential relevance of attachment within a multifactorial model of SUDs. But there will still be a lot of theoretical and empirical work to be done to integrate it into a concise model. Methodological problems in the assessment of attachment and substance abuse limit comparability. There is a tendency in many studies to focus on attachment as a single variable and to disregard its context and possible confounds. Future research will have to compare different groups of substance abusers systematically, including 
severity of substance use and comorbid disorders, linking psychological and neurobiological measures. We will need more longitudinal studies covering longer periods of time to completely understand the developmental pathways from attachment to SUDs. This review has not considered family systems of substance abusers or preventive aspects for children of substance-abusing parents. We will have to move to the level of systems and integrate

\section{REFERENCES}

1. Schindler A, Thomasius R, Sack PM, Gemeinhardt B, Küstner UJ, Eckert J. Attachment and substance use disorders: a review of the literature and a study in drug dependent adolescents. Attach Hum Dev (2005) 7(3):207-28. doi: 10.1080/14616730500173918

2. West R, Brown, J. Theory of Addiction. Oxford, UK: Wiley Addiction Press (2013). doi: 10.1002/9781118484890

3. Bowlby J. Attachment and loss. Vol.1: attachment. New York: Basic Books (1969).

4. Bowlby J. Attachment and loss. Vol.2: separation: anxiety and anger. New York: Basic Books (1973).

5. Bowlby J. Attachment and loss. Vol.3: loss: sadness and depression. New York: Basic Books (1980).

6. Bateman AW, Fonagy P. Borderline personality disorder. In: Bateman, AW, and Fonagy, P, editors. Handbook of mentalizing in mental health practice. Washington, D.C.: American Psychiatric Publishing (2012). p. 273-88.

7. Holmes J. Exploring in security. London UK: Routledge (2010).

8. Schindler A, Bröning S. A review on attachment and adolescent substance abuse: empirical evidence and implications for prevention and treatment. Subs Abuse J (2015), 36(3):304-13. doi: 10.1080/08897077.2014.983586

9. van IJzendoorn MH, Bakermans-Kranenburg MJ. Attachment representations in mothers, fathers, adolescents and clinical groups: a metaanalytic search for normative data. J Consult Clin Psychol (1996) 64/1:8-21. doi: 10.1037/0022-006X.64.1.8

10. Mikulincer M, Shaver PR. Attachment in adulthood. Guilford: New York (2007).

11. Petraitis J, Flay BR, Miller TQ, Torpy EJ, Greiner B. Illicit substance use among adolescents: a matrix of prospective predictors. Subst Use Misuse (1998) 33(13):2561-604. doi: 10.3109/10826089809059341

12. Khantzian EJ. The self-medication hypothesis of substance use disorders: a reconsideration and recent applications. Harv Rev Psychiatry (1997) 4:23144. doi: 10.3109/10673229709030550

13. Unterrainer HF, Hiebler-Ragger M, Rogen L, Kapfhammer HP. Sucht als Bindungsstörung. [Addiction as an attachment disorder]. Nervenarzt (2018) 89:1043-8. doi: 10.1007/s00115-017-0462-4

14. Iglesias EB, Fernández Del Río E, Calafat A, Fernadez-Hermida JR. Attachment and substance use in adolescence: a review of conceptual and methodological aspects. Adicciones (2014) 26(1):77-86. doi: 10.20882/ adicciones.137

15. Julien RM, Advokat CD, Comaty J. A primer of drug action. New York: Worth Publishers (2010).

16. Klein M. Psychosoziale Aspekte des Risikoverhaltens Jugendlicher im Umgang mit Suchtmitteln. Gesundheitswesen 2004 (2004) 66:56-60. doi: 10.1055/s-2004-812769

17. Philips B, Kahn U, Bateman AW. Drug addiction. In: Bateman, AW, and Fonagy, P, editors. Handbook of mentalizing in mental health practice. Washington, D.C.: American Psychiatric Publishing (2012). p. 445-62.

18. Thorberg FA, Livers M. Attachment, fear of intimacy and differentiation of self among clients in substance disorder treatment facilities. Addict Behav (2006) 31(4):732-7. doi: 10.1016/j.addbeh.2005.05.050

19. Alvarez-Monjaras M, Mayes LC, Potenza MN, Rutherford HJ. A developmental model of addictions: integrating neurobiological and psychodynamic theories through the lens of attachment. Attach Hum Dev (2018) 18:1-22. doi: 10.1080/14616734.2018.1498113 family contexts into the study of attachment, linking attachment representations with relationship behavior and substance abuse.

\section{AUTHOR CONTRIBUTIONS}

The author confirms being the sole contributor of this work and has approved it for publication.

20. Suchman NE, DeCoste CL. Substance abuse and addiction-implications for early relationships and interventions. Zero Three (2018) 38(5):17-22.

21. Lyons-Ruth K, Jacobvitz D. Attachment disorganization. In: Cassidy, J, and Shaver, PR, editors. Handbook of attachment. New York, NY: Guilford; (2008). p. 666-97.

22. Shaver PR, Mikulincer M. Attachment-related psychodynamics. Attach Hum Dev (2002) 4(2):133-61. doi: 10.1080/14616730210154171

23. Bartholomew K, Horowitz LM. Attachment styles among young adults: a test of a four-category model. J Pers Soc Psychol (1991) 61(2):226-44. doi: 10.1037//0022-3514.61.2.226

24. Ravitz P, Maunder R, Hunter J, Sthankiva B, Lancee W. Adult attachment measures: a 25-year review. J Psychosom Res (2010) 69(4):419-32. doi: 10.1016/j.jpsychores.2009.08.006

25. Trigo JM, Martin-García E, Berrendero F, Robledo P, Maldonado R. The endogenous opioid system: a common substrate in drug addiction. Drug Alcohol Depend (2010) 108(3):183-94. doi: 10.1016/j.drugalcdep. 2009.10.011

26. Burkett JP, Young LJ. The behavioral, anatomical and pharmacological parallels between social attachment, love and addiction. Psychopharmacology (2012) 224(1):1-26. doi: 10.1007/s00213-012-2794-x

27. Zellner MR, Watt DF, Solms M, Panksepp J. Affective neuroscientific and neuropsychoanalytic approaches to two intractable psychiatric problems: why depression feels so bad and what addicts really want. Neurosci Biobehav Rev (2011) 35(9):2000-8. doi: 10.1016/j.neubiorev.2011.01.003

28. Insel TR. Is social attachment an addictive disorder? Physiol Behav (2003) 79:351-7. doi: 10.1016/S0031-9384(03)00148-3

29. Panksepp J, Knutson B, and Burgdorf J. The role of brain emotional systems in addictions: a neuro-evolutionary perspective and a newself-reportanimal model. Addiction (2002) 97(4):459-69. doi: 10.1046/j.1360-0443.2002. 00025.x

30. Nutt DJ, Lingford-Hughes A, Erritzoe D, Stokes PR. The dopamine theory of addiction: 40 years of highs and lows. Nat Rev Neurosci (2015) 16(5):305-12. doi: $10.1038 / \mathrm{nrn} 3939$

31. Blum K, Thanos PK, Oscar-Berman M, Febo M, Baron D, Badgaiyan RD, et al. dopamine in the brain: hypothesizing surfeit or deficit links to reward and addiction. J Reward Defic Syndr (2015) 1(3):95-104. doi: 10.17756/ jrds.2015-016

32. Byng-Hall J. Family and couple therapy: toward greater security. In: Cassidy, J, and Shaver, PR, editors. Handbook of attachment. New York, NY: Guilford (1999). p. 625-45.

33. Allen JP, Land D. Attachment in adolescence. In: Cassidy, J, and Shaver, PR, editors. Handbook of attachment. New York, NY: Guilford (1999). p. 319-35.

34. Main M, Goldwyn R. Adult attachment scoring and classification system. Unpublished manuscript. Berkeley, CA: University of California at Berkeley (1998).

35. Melnick S, Finger B, Hans S, Patrick M, Lyons-Ruth K. Hostile-helpless states of mind in the Adult Attachment Interview: a proposed additional AAI category with implications for identifying disorganized infant attachment in high-risk samples. In: Steele, $\mathrm{H}$, and Steele, M, editors. Clinical applications of the Adult Attachment Interview. New York, NY: Guilford (2008). p. 399-423.

36. George C, West M. The development and preliminary validation of a new measure of adult attachment: the adult attachment projective. Attach Hum Dev (2001) 3(1):30-61. doi: 10.1080/14616730010024771

37. Hazan C, Shaver P. Conceptualizing romantic love as an attachment process. J Pers Soc Psychol (1987) 52:511-24. doi: 10.1037//0022-3514.52.3.511 
38. Collins NL, Read SJ. Adult attachment, working models, and relationship quality in dating couples. J Personal Soc Psychol (1990) 58(4):644. doi: 10.1037/0022-3514.58.4.644

39. Griffin DW, Bartholomew K. The metaphysics of measurement: the case of adult attachment. In: Bartholomew, K, and Perlman, D, editors. Attachment processes in adulthood. Advances in personal relationships., vol. 5 London, UK: Jessica Kingsley (1994). p. 17-52.

40. Brennan KA, Clark CL,Shaver PR. Self-report measurement of adult romantic attachment: an integrative overview. In: Simpson, JA, and Rholes, WS, editors. Attachment theory and close relationships. New York NY:Guilford Press (1998). p. 46-76.

41. Cooper ML, Shaver PR, Collins NL. Attachment styles, emotion regulation and adjustment in adolescence. J Pers Soc Psychol (1998) 74(5):1380-97. doi: 10.1037//0022-3514.74.5.1380

42. Delvecchio E, Di Riso D, Lis A, Salcuni S. Adult attachment, social adjustment, and well-being in drug-addicted inpatients. Psychol. Rep. (2016) 118(2):587-607. doi: 10.1177/0033294116639181

43. Amann U. Bindungsrepräsentationen suchmittelabhängiger Jugendlicher und ihrer Eltern [Attachment representations in drug addicted youths and their parents]. Norderstedt, Germany: GRIN (2009).

44. Branstetter SA, Furman W, Cottrell L. The influence of representations of attachment, maternal-adolescent relationship quality, and maternal monitoring on adolescent substance use: a two-year longitudinal examination. Child. Dev. (2009) 80(5):1448-62. doi: 10.1111/j.1467-8624.2009.01344.x

45. Finger B. Exploring the intergenerational transmission of Attachment disorganization. Chicago, IL: University of Chicago IL (2006).

46. Caspers KM, Cadoret RJ, Langbehn D, Yucuis R, Troutman B. Contributions of attachment style and perceived social support to lifetime use of illicit substances. Addict Behav (2005) 30(5):1007-11. doi: 10.1016/j. addbeh.2004.09.001

47. Caspers KM, Yucuis R, Troutman B, Spinks R. Attachment as an organizer of behavior: implications for substance abuse problems and willingness to seek treatment. Subst Abuse Treat Prev Policy (2006) 1(32). doi: 10.1186/1747-597X-1-32

48. Riggs SA, Jacobvitz D. Expectant parents' representations of early attachment relationships: associations with mental health and family history. J Consult Clin Psychol (2002) 70(1):195-204. doi: 10.1037//0022-006X.70.1.195

49. Fonagy P, Leigh T, Steele M, Steele H, Kennedy R, Mattoon G, et al. The relation of attachment status, psychiatric classification and response to psychotherapy. J Consult Clin Psychol (1996) 64(1):22-31. doi: 10.1037/ 0022-006X.64.1.22

50. Rosenstein DS, Horowitz HA. Adolescent attachment and psychopathology. J. Consult Clin Psychol (1996) 642:244-53. doi: 10.1037/0022-006X.64.2.244

51. Allen JP, Hauser ST, Borman-Spurell E. Attachment theory as a framework for understanding sequelae of severe adolescent psychopathology: an 11-year follow-up study. J Consult Clin Psychol (1996) 64(2):254-63. doi: 10.1037//0022-006X.64.2.254

52. Finzi-Dottan R, Cohen O, Iwaniec D, Sapir Y, Weizman A. The drug-user husband and his wife: attachment styles, family cohesion and adaptability. Subst Use Misuse (2003) 38(2):271-92. doi: 10.1081/JA-120017249

53. Mickelson KD, Kessler RC, Shaver PR. Adult attachment in a nationally representative sample. J Pers Soc Psychol (1997) 73(5):1092-106. doi: 10.1037//0022-3514.73.5.1092

54. Brennan KA, Shaver PR. Dimensions of adult attachment, affect regulation, and romantic relationship functioning. Pers Soc Psychol Bull (1995) 21:267-83.

55. Senchak M, Leonard KE. Attachment styles and marital adjustment among newlywed couples. J Soc Pers Relat (1992) 9:61-4. doi: 10.1177/ 0265407592091003

56. Durjava L. Relationship between recalled parental bonding, adult attachment patterns and severity of heroin addiction. MOJ Addict Med Ther (2018) 54:168-74. doi: 10.15406/mojamt.2018.05.00114

57. Unterrainer HF, Hiebler-Ragger M, Koschutnig K, Fuchshuber J, Tscheschner S, Url M, et al. Addiction as an attachment disorder-white matter impairment is linked to increased negative affective states in polydrug use. Fron (2017) doi: 10.3389/fnhum.2017.00208
58. Mortazavi Z, Sohrabi F, Hatami HR. Comparison of attachment styles and emotional maturity between opiate addicts and non-addicts. Ann Biol Res (2012) 31:409-14

59. Shin SE, Kim NS, Jang EY. Comparison of problematic internet and alcohol use and attachment styles among industrial workers in Korea. Cyberpsychol. Behav Soc Netw (2011) 14(11):665-72. doi: 10.1089/cyber.2010.0470

60. Kassel JD, Wardle M, Roberts JE. Adult attachment security and college student substance use. Addict Behav (2007) 32(6):1164-76. doi: 10.1016/j. addbeh.2006.08.005

61. Vaz-Serra A, Canavarro MC, Ramalheira C. The importance of family context in alcoholism. Alcohol Alcohol (1998) 331:37-41. doi: 10.1093/ oxfordjournals.alcalc.a008345

62. Gidhagen Y, Holmqvist R, Philips B. Attachment style among outpatients with substance use disorders in psychological treatment. Psychol Psychother (2018) 91(4):490-508. doi: 10.1111/papt.12172

63. Le TL, Levitan RD, Mann RE, Maunder RG. Childhood adversity and hazardous drinking: the mediating role of attachment insecurity. Subst Use Misuse (2018) 3:53(8):1387-98. doi: 10.1080/10826084.2017.1409764

64. Schindler A, Sack PM. Comorbid substance use disorders are related to avoidant attachment in individuals with borderline disorders. Journal of Mental and Nervous Diseases (2015) 203:820-6. doi: 10.1097/ NMD.0000000000000377

65. Wedekind D, Bandelow B, Heitmann S, Havemann-Reinecke U, Engel KR, Huether G. Attachment style, anxiety coping, and personality-styles in withdrawn alcohol addicted inpatients. Subst Abuse Treat Prev Policy (2013) 8:1. doi: 10.1186/1747-597X-8-1

66. Jenkins CO, Tonigan JS. Attachment avoidance and anxiety as predictors of 12-step group engagement. J Stud Alcohol Drugs (2011) 72(5):854-63. doi: 10.15288/jsad.2011.72.854

67. Harnic D, Digiacomantonio V, Innamorati M, Mazza M, Di Marzo S, Sacripanti F, et al. Temperament and attachment in alcohol addicted patients of type 1 and 2. Riv Psichiatr (2010) 45(5):311-9. doi 10.1708/530.6319

68. Molnar DS, Sadava SW, DeCourville NH, Perrier CP. Attachment, motivations, and alcohol: testing a dual-path model of high-risk drinking and adverse consequences in transitional clinical and student samples. Can J Behav (2010) 42(1):1-13. doi: 10.1037/a0016759

69. DeRick A, Vanheule S. Attachment styles in alcoholic inpatients. Addict Res (2007) 13:101-8. doi: 10.1159/000097940

70. DeRick A, Vanheule S, Verhaeghe P. Alcohol addiction and the attachment system: an empirical study of attachment style, alexithymia, and psychiatric disorders in alcoholic inpatients. Subst Use Misuse (2009) 44(1):99-104. doi: $10.1080 / 10826080802525744$

71. Schindler A, Thomasius R, Petersen K, Sack PM. Heroin as an attachment substitute? Attach. Hum. Dev. (2009) 11:307-30. doi: 10.1080/14616730902815009

72. Doumas DM, Blasey CM, Mitchell S. Adult attachment, emotional distress, and interpersonal problems in alcohol and drug dependency treatment. Alcohol Treat Q (2006) 24(4):41-54. doi: 10.1300/J020v24n04_04

73. Vungkhanching M, Sher KJ, Jackson KM, Parra GR. Relation of attachment style to family history of alcoholism and alcohol use disorders in early adulthood. Drug Alcohol Depend (2004) 75(1):47-53. doi: 10.1016/j. drugalcdep.2004.01.013

74. McNally AM, Palfai TP, Levine RV, Moore BM. Attachment dimensions and drinking-related problems among young adults: the mediational role of coping motives. Addict Behav (2003) 28(6):1115-27. doi: 10.1016/ S0306-4603(02)00224-1

75. Zeid D, Carter J, Lindberg M. Comparisons of alcohol and drug dependence in terms of attachments and clinical issues. Subst Use Misuse (2017) 53(1):18. doi: $10.1080 / 10826084.2017 .1319865$

76. Zhai ZW, Kirisci L, Tarter RE, Ridenour TA. Psychological dysregulation during adolescence mediates the association of parent-child attachment in childhood and substance use disorder in adulthood. Am. J Drug Alcohol Abuse (2014) 40(1):67-74. doi: 10.3109/00952990.2013.848876

77. Danielsson AK, Romelsjoe A, Tengstroem A. Heavy episodic drinking in early adolescence: gender specific risk and protective factors. Subst Use Misuse (2011) 46(5):633-43. doi: 10.3109/10826084.2010.528120 
78. Jordan S, Sack PM. Schutz- und Risikofaktoren [Protective factors and risk factors]. In: Thomasius, R, Schulte-Markwort, M, Küstner, UJ, and Riedesser, $\mathrm{P}$, editors. Suchtstoerungen im Kindes- und Jugendalter-Das Handbuch: Grundlagen und Praxis. Stuttgart, Germany: Schattauer (2009). p. 127-38.

79. Leonard KE, Eiden RD. Marital and family processes in the context of alcohol use and alcohol disorders. Annu Rev Clin Psychol (2007) 3:285-310. doi: 10.1146/annurev.clinpsy.3.022806.091424

80. Fairbairn CE, Briley DA, Kang D, Fraley RC, Hankin BL, Ariss T. A meta-analysis of longitudinal associations between substance use and interpersonal attachment security. Psychol Bull (2018) 144(5):532-55. doi: 10.1037/bul0000141

81. Schäfer I. Traumatisierung und Sucht [Trauma and addiction]. In: Seidler, G, Freyberger H, and Maercker, A, editors. Handbuch psychotraumatologie. Stuttgart, Germany: Klett-Cotta (2011). p. 255-63.

82. Fowler JC, Groat M, Ulanday M. Attachment style and treatment completion among psychiatric inpatients with substance use disorders. Am J Addict (2013) 22(1):14-7. doi: 10.1111/j.1521-0391.2013.00318.x

83. Rowe CL. Family therapy for drug abuse: review and updates 20032010. J Marital Fam Ther (2012) 38(1):59-81. doi: 10.1111/j.1752-0606. 2011.00280.x

84. von Sydow K, Retzlaff R, Beher S, Haun ML, Schweitzer J. (2013). The efficacy of systemic therapy for childhood and adolescent externalizing disorders: A Systematic Review of 47 RCT. Fam Process 52(4):576-618. doi: 10.1111/ famp. 12047
85. Diamond, GM, Diamond, GS, Hogue, A. Attachment-based family therapy: adherence and differentiation. J Marital Fam Ther (2007) 33:177-91. doi: 10.1111/j.1752-0606.2007.00015.x

86. Asen E, Fonagy P. Mentalization-based family therapy. In: Bateman, AW, and Fonagy, P, editors. Handbook of mentalizing in mental health practice. Washington, D.C.: American Psychiatric Publishing (2012). p. 107-28.

87. Schindler A, Thomasius R, Sack PM, Gemeinhardt B, Küstner U. Insecure family bases and adolescent drug abuse: a new approach to family patterns of attachment. Attach Hum Dev (2007) 9(2):111-26. doi: 10.1080/ 14616730701349689

88. Pedersen CA. Oxytocin, tolerance and the dark side of addiction. Int Rev Neurobiol (2017) 136:239-74. doi: 10.1016/bs.irn.2017.08.003

Conflict of Interest: The author declares that the research was conducted in the absence of any commercial or financial relationships that could be construed as a potential conflict of interest.

Copyright (c) 2019 Schindler. This is an open-access article distributed under the terms of the Creative Commons Attribution License (CC BY). The use, distribution or reproduction in other forums is permitted, provided the original author(s) and the copyright owner(s) are credited and that the original publication in this journal is cited, in accordance with accepted academic practice. No use, distribution or reproduction is permitted which does not comply with these terms. 